\title{
Limestone reaction in calcium aluminate cement-calcium sulfate systems
}

\author{
Julien Bizzozero *, Karen L. Scrivener \\ Laboratory of Construction Materials, École Polytechnique Fédérale de Lausanne (EPFL), Station 12, 1015 Lausanne, Switzerland
}

\section{A R T I C L E I N F O}

\section{Article history:}

Received 18 June 2014

Accepted 7 May 2015

Available online $\mathrm{xxxx}$

\section{Keywords:}

Hydration (A)

Thermodynamic calculations (B)

Compressive strength (C)

Ettringite (D)

Supplementary cementitious materials

\begin{abstract}
A B S T R A C T
This paper reports a study of ternary blends composed of calcium aluminate cement, calcium sulfate hemihydrate and limestone. Compressive strength tests and hydration kinetics were studied as a function of limestone and calcium sulfate content. The phase evolution and the total porosity were followed and compared to thermodynamic simulation to understand the reactions involved and the effect of limestone on these binders. The reaction of limestone leads to the formation of hemicarboaluminate and monocarboaluminate. Increasing the ratio between sulfate and aluminate decreases the extent of limestone reaction.
\end{abstract}

(c) 2015 Elsevier Ltd. All rights reserved.

\section{Introduction}

Ternary blends composed of calcium aluminate cement (CAC), calcium sulfate $\left(\mathrm{C}^{1}\right)$ and Portland cement $(\mathrm{PC})$ are widely used in dry mix mortars. These systems have special properties, such as fast setting, rapid strength development and shrinkage compensation that justify their use despite the higher costs with respect to plain PC.

In this study PC is replaced by limestone in ternary blends. Limestone is a low cost and a low environmental impact material. The literature on blends of calcium aluminate cement, calcium sulfate and limestone is scarce, nevertheless there are various studies with calcium sulfoaluminate cement (CSA) blended with calcium sulfate and limestone. Previous studies done by Pelletier-Chaignat et al. [1] on systems with similar chemical compositions containing CSA, gypsum and limestone or quartz filler indicate that limestone gives higher strengths compared to quartz. Hemicarboaluminate and monocarboaluminate are formed and there is less monosulfoaluminate. The impact of calcium sulfate on the limestone reaction was not discussed. Other studies on blends of CSA with calcium carbonate $[2,3]$ and of blends of CAC with calcium sulfate [4] showed that calcium sulfate has a strong impact on the reaction of calcium carbonate; the amount of reacted limestone decreases with the calcium sulfate content.
Limestone addition in cement has been widely studied in PC based systems [5-7]. These studies indicate that:

- The addition of calcite reduces ettringite dissolution when sulfate is depleted. Aluminate reacts with carbonates to form the AFm phases monocarboaluminate and hemicarboaluminate instead of consuming ettringite to form monosulfoaluminate.

- The formation of carboaluminates and increased amount of ettringite increase the volume of hydrates, decrease the porosity and increase the strength at modest levels of addition.

- The amount of calcite which can react is limited by the reactive aluminate and sulfate content in the system. Above a critical sulfate to aluminate ratio, calcite acts as inert filler.

The main difference between PC and CAC-C\$ based systems is that the latter clearly contains much higher quantities of aluminate, mainly in the form of monocalcium aluminate, so there is potential for much higher amounts of calcite to react and contribute to strength development.

The hydration of systems composed of CAC and calcium sulfate leads to the formation of ettringite and amorphous aluminium hydroxide as shown in reaction (1):

$3 \mathrm{CA}+3 \mathrm{C} \$ \mathrm{H}_{\mathrm{x}}+(38-3 \mathrm{x}) \mathrm{H} \rightarrow \mathrm{C}_{3} \mathrm{~A} \cdot 3 \mathrm{C} \$ \cdot \mathrm{H}_{32}+2 \mathrm{AH}_{3}$

where $\mathrm{x}=0$ for anhydrite, $\mathrm{x}=0.5$ for hemihydrate and $\mathrm{x}=2$ for gypsum.

\footnotetext{
* Corresponding author. Tel.: +412169 37786; fax: +41216935800.

E-mail address: julien.bizzozero@gmail.com (J. Bizzozero).

${ }^{1}$ Cement notation: $\mathrm{C}: \mathrm{CaO}, \mathrm{A}: \mathrm{Al}_{2} \mathrm{O}_{3}, \$: \mathrm{SO}_{3}, \mathrm{~S}: \mathrm{SiO}_{2}, \mathrm{c}: \mathrm{CO}_{2}, \mathrm{~F}: \mathrm{Fe}_{3} \mathrm{O}_{4}, \mathrm{H}: \mathrm{H}_{2} \mathrm{O}$.
} 


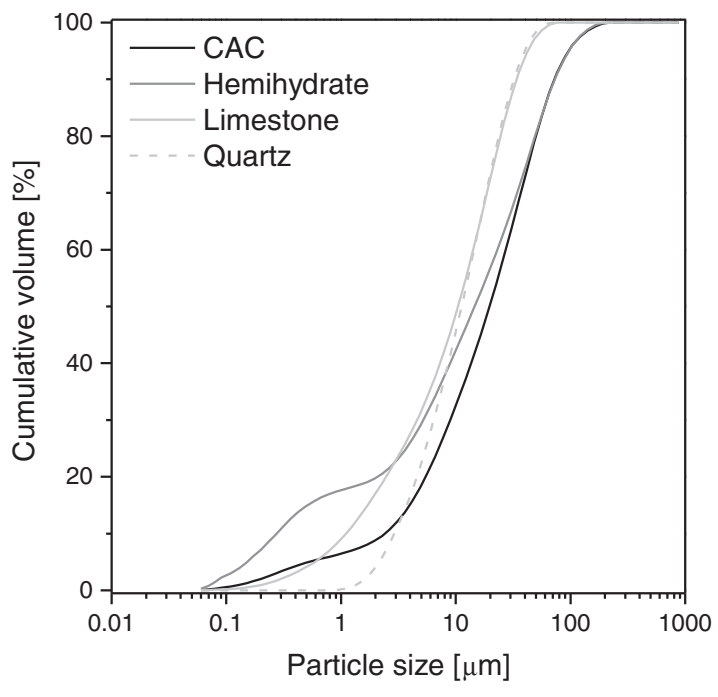

Fig. 1. Particle size distributions.

When calcium sulfate is depleted and there is an excess of monocalcium aluminate, ettringite is consumed and forms monosulfoaluminate and aluminium hydroxide according to reaction (2):

$\mathrm{C}_{3} \mathrm{~A} \cdot 3 \mathrm{C} \$ \cdot \mathrm{H}_{32}+6 \mathrm{CA}+16 \mathrm{H} \rightarrow 3 \mathrm{C}_{3} \mathrm{~A} \cdot \mathrm{C} \$ \cdot \mathrm{H}_{12}+4 \mathrm{AH}_{3}$.

When limestone is added to the system, the formation of hemicarboaluminate (reaction (3)) and/or monocarboaluminate (reaction (4)) is thermodynamically more favourable compared to the formation of monosulfoaluminate (reaction (2)), which is not stable anymore.

$3 \mathrm{CA}+0.5 \mathrm{Cc}+18 \mathrm{H} \rightarrow \mathrm{C}_{3} \mathrm{~A} \cdot \mathrm{Cc}_{0.5} \cdot \mathrm{H}_{12}+2 \mathrm{AH}_{3}$

$3 \mathrm{CA}+\mathrm{Cc}+17 \mathrm{H} \rightarrow \mathrm{C}_{3} \mathrm{~A} \cdot \mathrm{Cc} \cdot \mathrm{H}_{11}+2 \mathrm{AH}_{3}$

The main objective of this study is to investigate the effect of variable calcium sulfate and limestone content on strength development and link this to hydration kinetics, phase formation and the reaction of limestone. Thermodynamic simulation is used to understand the impact of calcium sulfate content on the phase assemblage of these systems and to estimate the maximal amount of reacted limestone.

\section{Materials and methods}

Calcium aluminate cement (CAC, Ternal RG from Kerneos), was blended with calcium sulfate $\beta$-hemihydrate $(\mathrm{HH}$, Prestia Selecta from Lafarge). Six systems with variable calcium sulfate content were studied; three without any substitution and three with $20 \mathrm{wt} . \%$ (weight percent) of limestone (Cc, natural crushed calcite, Durcal 15 from Omya). Systems substituted with quartz (Q) instead of limestone were also prepared for compressive strength tests and isothermal calorimetry measurements. This was done to separate the physical and the chemical effects of the substitution. The physical filler effect is the extra space due to dilution and the addition of surfaces for nucleation. The chemical effect is due to the reaction of limestone [8]. To have comparable physical effects it is important to have similar particle size distributions for quartz and limestone as shown in Fig. 1.

The oxide composition of the different materials obtained with X-ray fluorescence (XRF) spectrometry is given in Table 1. The mineralogical compositions of the CAC cement, hemihydrate and limestone were obtained by XRD Rietveld analysis and are presented in Table 2. CAC contains some $\mathrm{C}_{12} \mathrm{~A}_{7}$ (about 1.4\%) and is included in the column "other phases". Note that hemihydrate contains $3.5 \mathrm{wt}$.\% of calcite. The compositions of the systems studied are listed in Table 3. The sample names are composed of the molar percentage of CA relative to $\mathrm{HH}$ and the wt.\% of limestone substitution (Cc). Limestone is composed of $99.8 \%$ of calcite, therefore the terms limestone and calcite are used without distinction in this paper. Molar amounts of calcium sulfate are used to indicate the relative amount of aluminate and sulfate; the stoichiometry of reaction (1) is $50 \mathrm{~mol} \%$ aluminate and $50 \mathrm{~mol} \%$ sulfate. An additional system with 50CA-50HH was tested for compressive strength. Moreover different substitution levels $(10,20$ and $40 \%$ Cc) were tested in compression at 28 days of hydration.

All experiments were carried out at $20^{\circ} \mathrm{C}$. Paste samples were cast with a water to binder ratio $(\mathrm{w} / \mathrm{b})$ of 0.4 and were used for all the experiments except compressive strength tests which were done on mortars. The dry powders were weighted in a recipient of $250 \mathrm{ml}$ and dry mixed for $30 \mathrm{~s}$ before mixing all the powders with water for 2 min using a paddle mixer at $1600 \mathrm{rpm}$.

For the strength measurements, mortars were cast according to European standard EN 196-1 with a water to binder ratio of 0.5 (because of the interfacial transition zone $\mathrm{a} \mathrm{w} / \mathrm{b}$ of $0.5 \mathrm{in}$ mortar is comparable to 0.4 in paste). Three mortar bars of $40 \times 40 \times 160 \mathrm{~mm}^{3}$ were cast from a blend of $1350 \mathrm{~g}$ of normalized sand with $450 \mathrm{~g}$ of binder and $225 \mathrm{~g}$ of water. The mixing protocol was: $30 \mathrm{~s}$ at low speed to blend the dry powders, water added and mixed for $30 \mathrm{~s}$ at low speed, the sand is then added and mixed for $30 \mathrm{~s}$ at low speed followed by a break of $15 \mathrm{~s}$ and $60 \mathrm{~s}$ at high speed. The mixing duration was reduced from that specified in the norm because of the rapid setting of the systems. No setting regulating admixtures were used. After one day the bars were unmoulded and cured in a high humidity environment (96\% R.H.). The results at each time are an average of four compression tests.

Hydration kinetics were followed by isothermal calorimetry (TAM Air from TA Instruments). $10 \mathrm{~g}$ of cement paste (mixed outside the calorimeter) was introduced in a glass ampoule which was then sealed with a cap and placed in the calorimeter.

For SEM, XRD, TGA and MIP measurements, the samples were cast in polystyrene cylinders ( $35 \mathrm{~mm} \varnothing \times 50 \mathrm{~mm}$ ). These cylinders were immediately placed in a water bath at $20{ }^{\circ} \mathrm{C}$ to maintain a constant temperature for the first $24 \mathrm{~h}$. Then they were demoulded and placed in cylindrical recipients of $37 \mathrm{~mm}$ of diameter containing around $8 \mathrm{~g}$ of demineralized water per $95 \mathrm{~g}$ of sample mass to ensure a continuous supply of water while minimizing leaching. At each age, three slices of 2-3 mm thickness were cut from the cylinders and then immersed in isopropanol to stop the hydration. After 7 days in the solvent, they were stored in a desiccator under vacuum and over silica gel for 2 days to remove the alcohol, prevent carbonation and remove possible moisture. Stopping the hydration with isopropanol and storing the samples under vacuum have a detrimental effect on the crystallinity and

Table 1

XRF oxide composition (expressed in wt.\%) and mass attenuation coefficients referring to CuK $\alpha$ radiation (MAC).

\begin{tabular}{|c|c|c|c|c|c|c|c|c|c|c|c|c|}
\hline & $\mathrm{CaO}$ & $\mathrm{SiO}_{2}$ & $\mathrm{Al}_{2} \mathrm{O}_{3}$ & $\mathrm{Fe}_{2} \mathrm{O}_{3}$ & $\mathrm{MgO}$ & $\mathrm{Na}_{2} \mathrm{O}$ & $\mathrm{K}_{2} \mathrm{O}$ & $\mathrm{SO}_{3}$ & $\mathrm{TiO}_{2}$ & $\mathrm{P}_{2} \mathrm{O}_{5}$ & $\mathrm{CO}_{2}$ & MAC \\
\hline CAC & 36.6 & 4.1 & 40.3 & 16.3 & 0.1 & 0.0 & 0.0 & 0.3 & 1.8 & 0.2 & - & 97.4 \\
\hline $\mathrm{HH}$ & 38.5 & 0.9 & 0.0 & 0.0 & 0.2 & 0.0 & 0.0 & 52.8 & 0.0 & 0.0 & - & 73.3 \\
\hline $\mathrm{Cc}$ & 57.3 & 0.1 & 0.1 & 0.0 & 0.4 & 0.1 & 0.2 & 0.0 & 0.0 & 0.0 & 40.9 & 76.1 \\
\hline $\mathrm{Q}$ & 0.0 & 97.9 & 1.0 & 0.0 & - & - & 0.8 & - & 0.0 & 0.0 & - & - \\
\hline $\mathrm{MAC}\left[\mathrm{cm}^{2} / \mathrm{g}\right][9]$ & 124.0 & 36.0 & 31.7 & 214.9 & 28.6 & 25.0 & 122.3 & 44.5 & 124.6 & 39.7 & 9.4 & - \\
\hline
\end{tabular}


Table 2

XRD Rietveld analyses on anhydrous powders (Error of measurement $\pm 2 \%$ ).

\begin{tabular}{|c|c|c|c|c|c|c|c|c|c|c|c|}
\hline [wt.\%] & $\mathrm{CA}$ & $\mathrm{C}_{2} \mathrm{~S}$ & $\mathrm{C}_{4} \mathrm{AF}$ & CFT perovskite & $\mathrm{C}_{2} \mathrm{AS}$ & $\mathrm{C} \$ \mathrm{H}_{0.5}$ & $C \$$ & $\mathrm{Cc}$ & $\mathrm{SiO}_{2}$ & $\mathrm{Fe}_{3} \mathrm{O}_{4}$ & Other phases \\
\hline CAC & 50.7 & 4.6 & 10.9 & 10.0 & 12.3 & - & - & - & - & 6.3 & 5.2 \\
\hline $\mathrm{HH}$ & - & - & - & - & - & 89.7 & 5.0 & 3.5 & 1.8 & - & - \\
\hline $\mathrm{Cc}$ & - & - & - & - & - & - & - & 99.8 & 0.2 & - & - \\
\hline
\end{tabular}

water content of the hydrates, particularly ettringite [10,11]. It was reported that stopping the hydration with isopropanol causes a partial conversion of hemicarboaluminate into monocarboaluminate [12]. Despite these problems, the results should be comparable if the same preparation protocol is followed. The slices were then used for SEM and MIP analyses and were crushed into fine powder $(<100 \mu \mathrm{m})$ for XRD and TGA analyses. For XRD and TGA the hydration was stopped at $1,7,14,28,90,180$ and 365 days of hydration.

X-ray diffraction (XRD) analyses were done with a Philips X'Pert Pro PANalytical ( $\mathrm{CuK} \alpha, \lambda=1.54 \AA$ ) working in Bragg-Brentano geometry with a $2 \theta$-range of $5^{\circ}-65^{\circ}$. The $\mathrm{X}$-ray source was operated at $45 \mathrm{kV}$ and $40 \mathrm{~mA}$. The analyses were done on dry powders using the back loading technique to minimize preferred orientation.

Quantitative Rietveld analyses were done with the HighScore Plus 3.0.5 software and using the external standard method (with rutile Kronos $2300,96.2 \%$ crystalline, $\mathrm{TiO}_{2}$ ) for absolute quantification of the crystalline phases. Table 4 lists the crystal structures of the different phases used to simulate the experimental diffractograms. The detailed method for the quantification of the phases is indicated in $[13,14]$. The mass attenuation coefficient (MAC) referring to $\mathrm{CuK} \alpha$ radiation of each oxide is given in Table 1 and is used to calculate the mass attenuation coefficient of the analysed samples. The bound water content in the sample is taken as the mass loss between 20 and $600{ }^{\circ} \mathrm{C}$ from TGA, this value is needed for the MAC calculation.

Thermogravimetric analysis (TGA) was carried out using a Mettler Toledo TGA/SDTA851e. Around $50 \mathrm{mg}$ of ground cement paste was placed in alumina crucibles covered by aluminium lids to reduce carbonation before analysis. The temperature ranged from 30 to $1000{ }^{\circ} \mathrm{C}$ with a heating rate of $10{ }^{\circ} \mathrm{C} /$ min under $\mathrm{N}_{2}$ atmosphere to prevent carbonation. TGA is used to estimate the $\mathrm{AH}_{3}$ content by integrating from 220 to $300{ }^{\circ} \mathrm{C}$ (crystalline gibbsite, $\mathrm{AH}_{3}$, has $3 \mathrm{~mol}$ of water per mole of phase, but the water content may be somewhat different for the microcrystalline or amorphous aluminium hydroxide formed here). $\mathrm{AH}_{3}$ is only roughly estimated as in this range of temperatures there is also a secondary peak of carbonate AFm phases, which is only a small fraction of the main peak which occurs at lower temperatures and therefore could lead to small quantification errors.

The slices were impregnated under vacuum with an epoxy resin (EPOTEK 301) and polished with diamond spray ranging from 9 to $1 / 4 \mu \mathrm{m}$. The polished samples were examined by backscattered electrons (BSE) and energy dispersive X-ray (EDS, Bruker AXS XFlash Detector 4030) analyses in a scanning electron microscope (SEM, FEI Quanta 200) with an accelerating voltage of $15 \mathrm{kV}$.

Mercury intrusion porosimetry (MIP) was carried out on Thermo Scientific Pascal 140 and 440 machines with a pressure capacity of $400 \mathrm{MPa}$. Five pieces of samples of about $4 \times 5 \times 5 \mathrm{~mm}^{3}$ were used for the analysis. The total measured connected porosity includes pores down to $2 \mathrm{~nm}$.

Thermodynamic simulations were carried out using the GEMS-PSI $[31,32]$ software with thermodynamic data for aqueous species and other solids from the GEMS-PSI thermodynamic database [33] and the CEMDATA14 database from EMPA [34,35] for the cementitious phases. The simulation is done on simplified systems composed of the main phase of the calcium aluminate cement, i.e. monocalcium aluminate $(\mathrm{CA})$, hemihydrate $(\mathrm{HH})$ and limestone $(\mathrm{Cc})$. The results are obtained from the minimization of the Gibbs fee energy in the system and no kinetics are taken into account.

\section{Results and discussion}

\subsection{Compressive strength}

Fig. 2a shows the compressive strength of low calcium sulfate mortars (70CA-30HH) without substitution, with $20 \mathrm{wt} . \%$ of quartz and with $20 \mathrm{wt} . \%$ of limestone. The compressive strength of all systems increases with time. The quartz systems have the lowest compressive strength. In contrast, the limestone systems show compressive strengths similar or higher than the reference system without substitution from seven days.

The high calcium sulfate systems 50CA-50HH show higher compressive strength compared to the previous systems as shown in Fig. 2b. These systems show no significant difference between limestone and quartz additions, suggesting that limestone acts purely as filler in high sulfate environments.

Fig. 3 shows the compressive strength as a function of limestone substitution (0,10, 20 and 40 wt.\%) of mortars with 30, 40, 45 and $50 \mathrm{~mol} \%$ calcium sulfate at 28 days of hydration. The compressive strength increases with the calcium sulfate content whereas it decreases with the substitution level, except for the $30 \mathrm{~mol} \%$ calcium sulfate system where the maximum is reached at $10 \mathrm{wt} . \%$ limestone replacement. For the low calcium sulfate system, similar strengths are maintained up to $20 \mathrm{wt} . \%$ of limestone.

As described previously, one of the properties of these binders is shrinkage compensation or dimensional stability. This property is highly influenced by the calcium sulfate content in the system, i.e. the expansion compensating the shrinkage increases with the calcium sulfate content. A study on the mechanisms of expansion on binary CACgypsum systems [36] shows that above $40 \mathrm{~mol} \%$ of calcium sulfate the systems are highly expansive. Some of the blends studied could be expansive due to the high calcium sulfate content, but the main objective is to understand the reactions between limestone and CAC-calcium sulfate, therefore the dimensional stability was not studied.

\subsection{Hydration kinetics}

The heat evolution of the two systems with low and high calcium sulfate content is shown in Fig. 4. Fig. 4a shows the heat flow of the

\section{Table 3}

Studied compositions. The sample names are composed of the molar percentage of CA relative to $\mathrm{HH}$ and the wt.\% of limestone substitution (Cc).

\begin{tabular}{|c|c|c|c|c|c|c|}
\hline \multirow[t]{2}{*}{ Sample name } & $\mathrm{CA}$ & $\mathrm{HH}$ & CAC & $\mathrm{HH}$ & Cc or $\mathrm{Q}$ & \multirow{2}{*}{$\begin{array}{l}\text { Cc relative } \\
\text { to CA } \\
{[\mathrm{mol} . \%]}\end{array}$} \\
\hline & \multicolumn{2}{|c|}{ [mol.\%] } & \multicolumn{3}{|c|}{ [wt.\%] } & \\
\hline 70СА-30HН & 70 & 30 & 83.3 & 16.7 & 0.0 & 0.0 \\
\hline $60 \mathrm{CA}-40 \mathrm{HH}$ & 60 & 40 & 75.8 & 24.2 & 0.0 & 0.0 \\
\hline $55 \mathrm{CA}-45 \mathrm{HH}$ & 55 & 45 & 70.5 & 29.5 & 0.0 & 0.0 \\
\hline 70СA-30HH-20Cc & 70 & 30 & 66.7 & 13.3 & 20.0 & 48.3 \\
\hline $60 \mathrm{CA}-40 \mathrm{HH}-20 \mathrm{Cc}$ & 60 & 40 & 60.6 & 19.4 & 20.0 & 50.7 \\
\hline $55 \mathrm{CA}-45 \mathrm{HH}-20 \mathrm{Cc}$ & 55 & 45 & 56.4 & 23.6 & 20.0 & 52.5 \\
\hline $\begin{array}{l}\text { 50CA-50HH-20Cc } \\
\text { (only for compressive strength tests) }\end{array}$ & 50 & 50 & 53.4 & 26.6 & 20.0 & 53.8 \\
\hline
\end{tabular}

Substitution should be at constant volume. As densities are very similar, 2.65 for quartz and $2.71\left[\mathrm{~g} / \mathrm{cm}^{3}\right]$ for limestone, there is not much difference in volume when adding 20 wt.\% of powder. 
Table 4

Phases and references used for quantitative Rietveld analyses.

\begin{tabular}{lll}
\hline Phase & ICSD code & Ref \\
\hline $\mathrm{CA}$ & 260 & {$[15]$} \\
$\mathrm{C}_{4} \mathrm{AF}$ & 2842 & {$[17]$} \\
$\mathrm{C}_{2} \mathrm{~S}$ & 81096 & {$[19]$} \\
$\mathrm{CFT}$ & 79353 & {$[21]$} \\
$\mathrm{C}_{2} \mathrm{AS}$ & 67689 & {$[23]$} \\
Magnetite & 158745 & {$[25]$} \\
Calcite & 73446 & {$[27]$} \\
Gypsum & 151692 & {$[29]$} \\
Hemihydrate & 92947 & {$[16]$} \\
Ettringite & 155395 & {$[18]$} \\
Monosulfoaluminate & 100138 & {$[20]$} \\
Gibbsite & 6162 & {$[22]$} \\
Monocarboaluminate & 59327 & {$[24]$} \\
Hemicarboaluminate & - & {$[26]$} \\
$\mathrm{C}_{3} \mathrm{AH}_{6}$ & 34227 & {$[28]$} \\
$\mathrm{C}_{2} \mathrm{ASH}_{8}$ & 69413 & {$[30]$} \\
\hline
\end{tabular}

low calcium sulfate system with limestone and quartz substitution (70CA-30HH-20Cc and 20Q). The heat flow of the system with higher calcium sulfate content (60CA-40HH-20Cc and 20Q) is presented in Fig. 4b. During the first peak (between 1 and $1 \mathrm{~h} 30 \mathrm{~min}$ ), hemihydrate dissolves and gypsum precipitates. The second peak is characterized by CA and gypsum dissolution and precipitation of the main phases ettringite and amorphous aluminium hydroxide as described by reaction (1). The origin of the third peak observed in the low calcium sulfate system is usually attributed to the depletion of gypsum and monosulfoaluminate starts to precipitate $[37,38]$. The height of the first peak is proportional to the amount of hemihydrate in the system. The time of occurrence of the first two peaks is similar for the low and high calcium sulfate systems. There is a negligible difference in hydration kinetics between the systems with limestone or quartz substitution and the cumulative heat of hydration is also similar for limestone and quartz as shown in Fig. 4c and d. The small difference can be attributed to the experimental error and/or to the small difference in particle size distribution according to Fig. 1. From these figures it is difficult to determine if the limestone is reacting: it seems to act as filler like quartz during the first 28 days of hydration. The heat generated in reactions (3) and (4) describing the formation of monocarboaluminate and hemicarboaluminate varies from 26 to $60 \mathrm{~J} / \mathrm{g} \mathrm{CAC}+\mathrm{C}$, respectively. These values were calculated from the enthalpies of the reactions

\section{a. $70 \mathrm{CA}-30 \mathrm{HH}$}

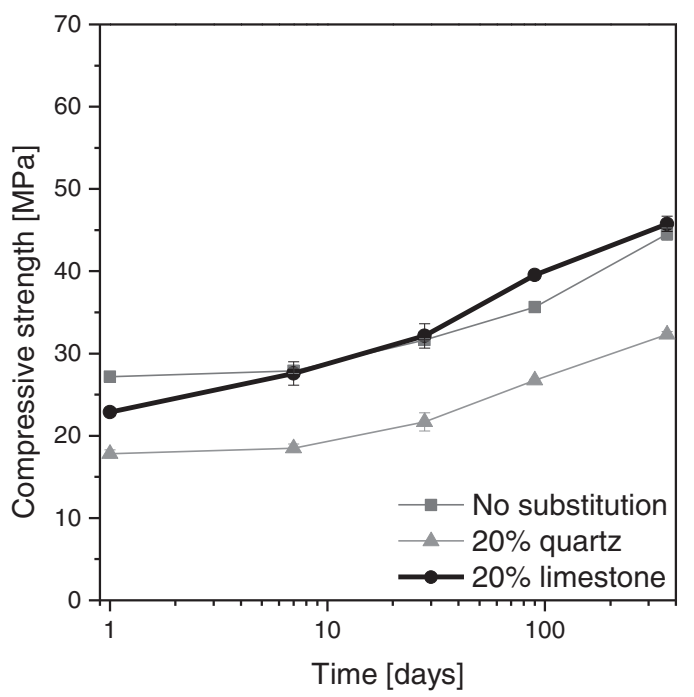

using the values from the CEMDATA14 database [34]. In the low sulfate systems there is a difference of around $20 \pm 10 \mathrm{~J} / \mathrm{g} C A C+C \$$, which is in the range of the heat that should be generated by the reactions described above. The experimental error is relatively high compared to the small differences due to limestone reaction; therefore calorimetry measurements cannot be used to detect the reaction of limestone. Nevertheless, the compressive strength tests confirm that limestone reacts from the first day in the low calcium sulfate system.

\subsection{Experimental and thermodynamic prediction}

The phase assemblages of the 3 calcium sulfate compositions studied with and without limestone substitution are presented in this section. The samples analysed with XRD, TGA and SEM were cured under water whereas the calorimetry samples were in sealed conditions. TGA was used to quantify the amount of bound water and this value is needed for Rietveld analyses. TGA does not give additional information compared to XRD quantitative results, except for the presence of amorphous aluminium hydroxide which is found in all the systems. The TGA results of the 70CA-30HH system are shown as an example in Fig. 5, the $\mathrm{AH}_{3}$ peak is at $\sim 260{ }^{\circ} \mathrm{C}$.

Fig. 6 shows the evolution of the anhydrous and hydrated phases for the different systems without (left) and with (right) limestone. The analyses were done at 1, 7, 14, 28, 90, 180 and 365 days of hydration. The data points are joined by straight lines as a guide only. Hemihydrate reacts rapidly and completely to form gypsum both of which are indicated as $\mathrm{C}_{\mathrm{SH}}$ in the figure.

In all the systems there is a rapid consumption of calcium sulfate and $\mathrm{CA}$ in the first day to form ettringite and $\mathrm{AH}_{3}$ (identifiable by TGA but part of amorphous in Fig. 6), according to reaction (1). Limestone addition enhances slightly the degree of hydration of CAC cement during the first day. This is the so-called filler effect; it is related to more available space or water for hydrates growth (i.e. when adding $20 \%$ of filler the $\mathrm{w} / \mathrm{b}$ ratio increases from 0.4 to 0.5 if limestone is considered inert at this age) and maybe to more nucleation sites $[8,39,40]$.

In the low sulfate systems (70CA-30HH) the amount of ettringite after one day decreases due to the lack of sulfate and monosulfoaluminate precipitates (reaction (2)). In the system with limestone only a small amount of monosulfoaluminate is formed and there is no significant decrease in the amount of ettringite. This is due to the formation of hemicarboaluminate and monocarboaluminate (indicated as $\mathrm{CO}_{3}-\mathrm{AFm}$ ) when $\mathrm{CaCO}_{3}$ is added to the system which consumes the

\section{b.50CA-50HH}

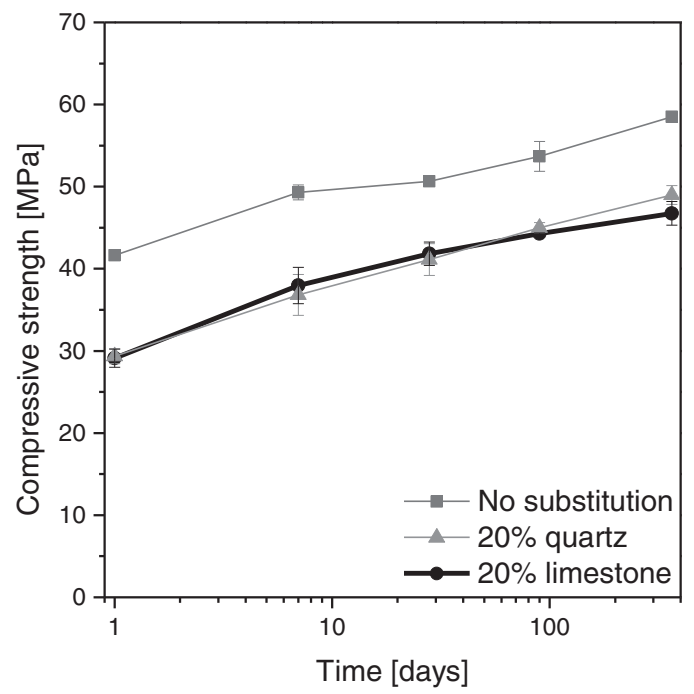

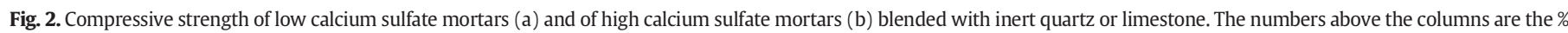
strength relative to the reference mortar without substitution. a.70CA-30HH. b.50CA-50HH. 


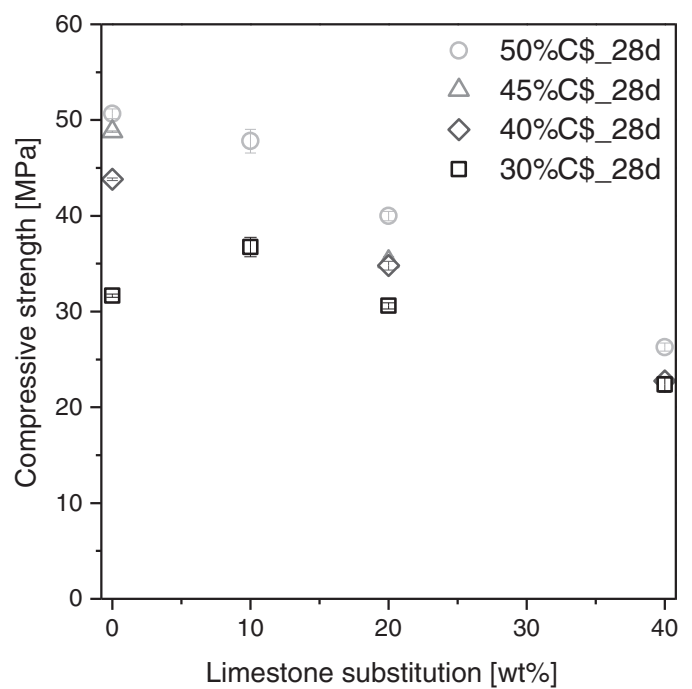

Fig. 3. Compressive strength as a function of limestone substitution for variable calcium sulfate amounts.

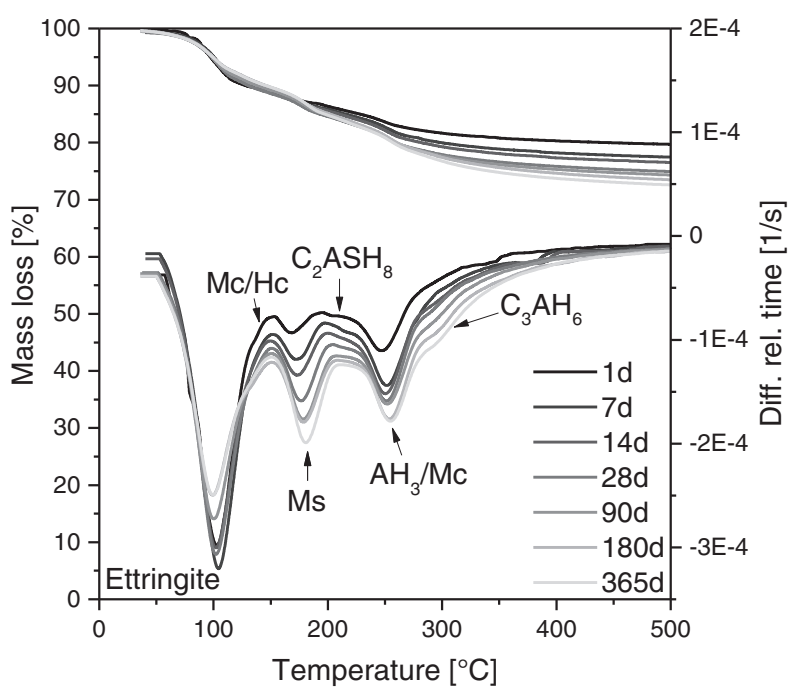

Fig. 5. TGA and DTG curves at various ages for the low calcium sulfate system without limestone (70CA-30HH). Phase abbreviations: monosulfoaluminate (Ms), hemicarboaluminate (Hc) and monocarboaluminate (Mc). a.

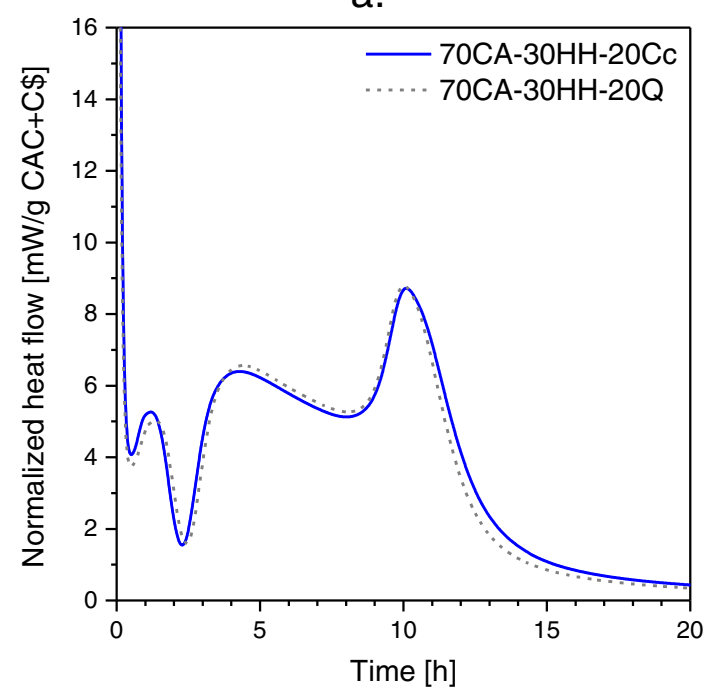

c.

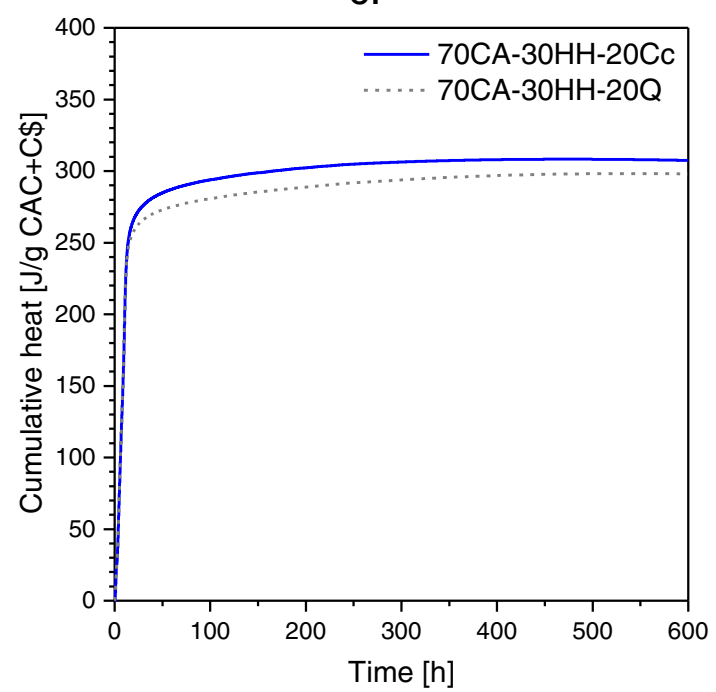

b.

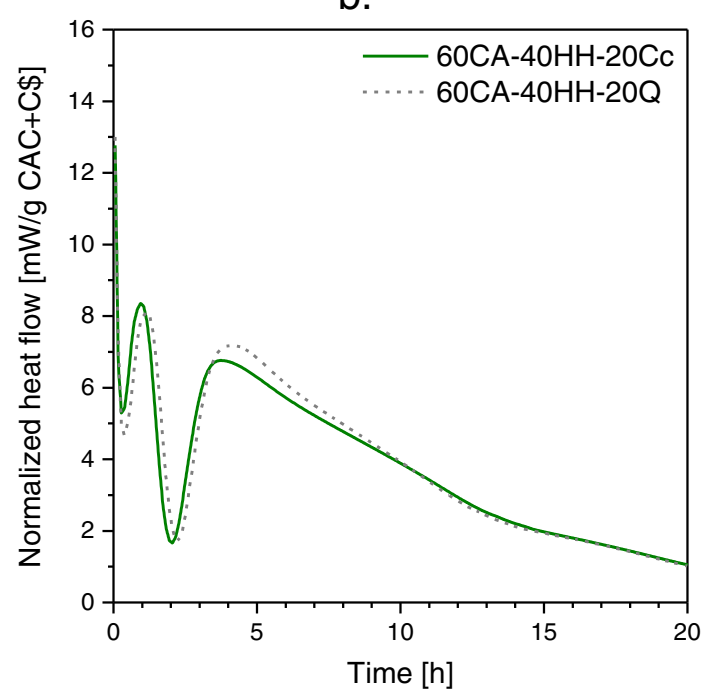

d.

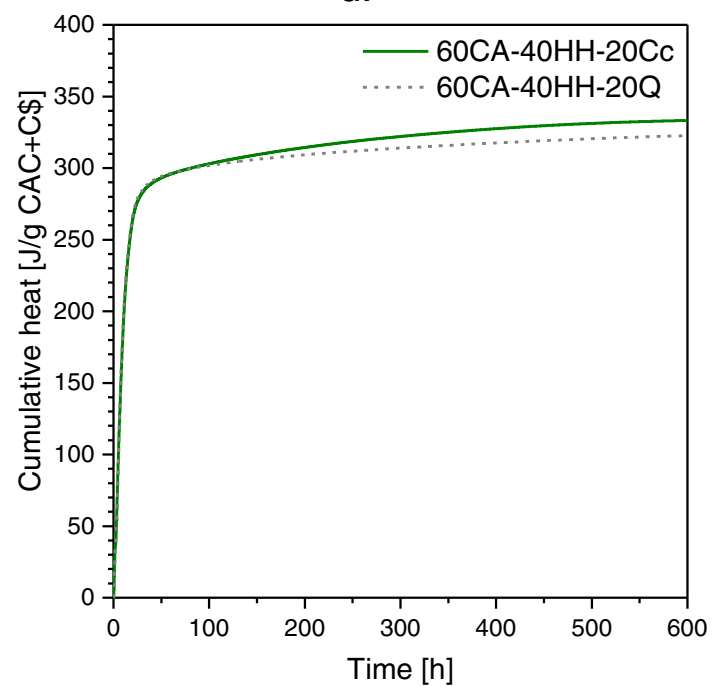

Fig. 4. Isothermal calorimetry measurements (heat flow a and b, cumulative heat c and d). 
a. $70 \mathrm{CA}-30 \mathrm{HH}$

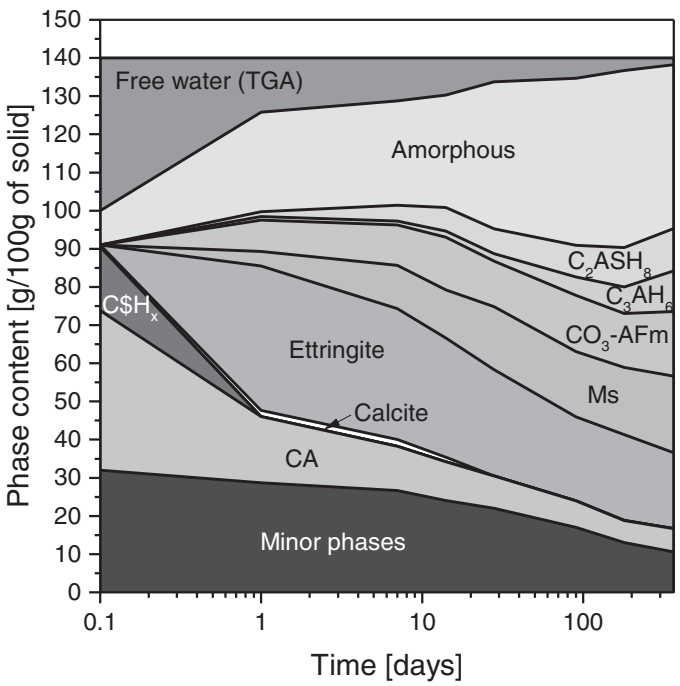

C. $60 \mathrm{CA}-40 \mathrm{HH}$

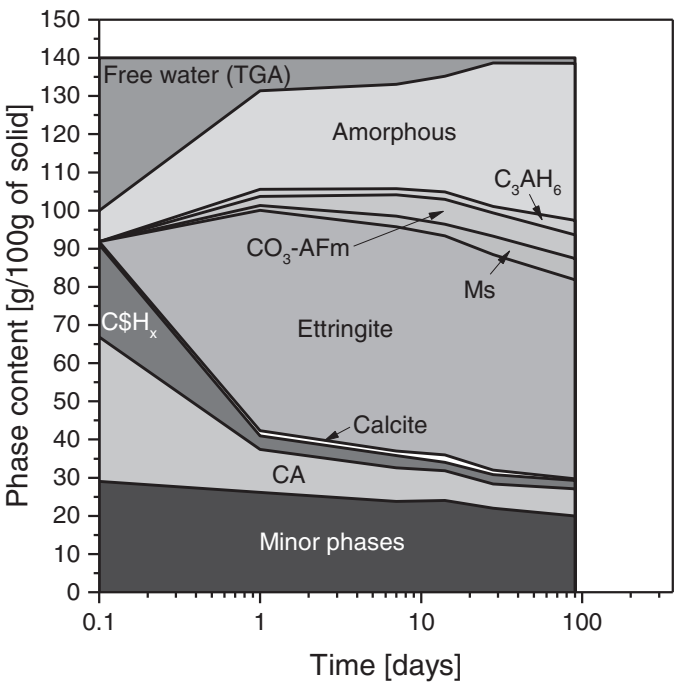

e. $55 \mathrm{CA}-45 \mathrm{HH}$

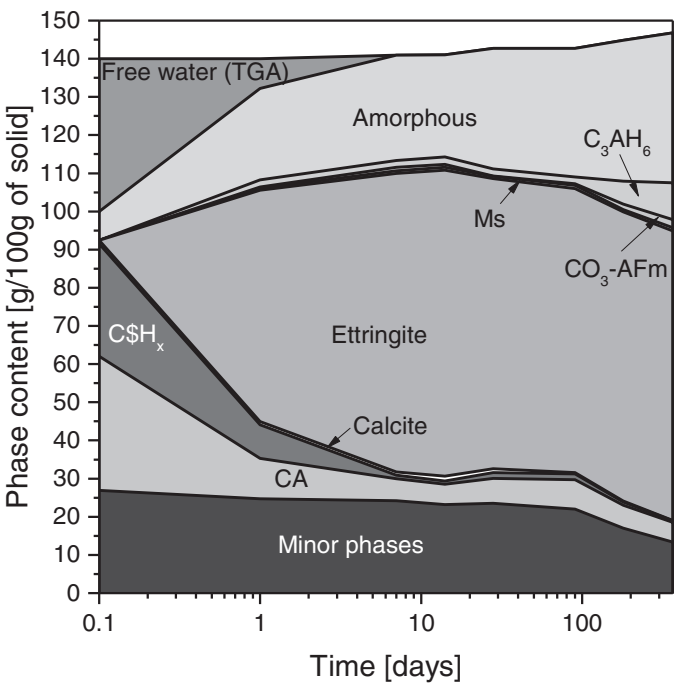

b. $70 \mathrm{CA}-30 \mathrm{HH}-20 \mathrm{Cc}$

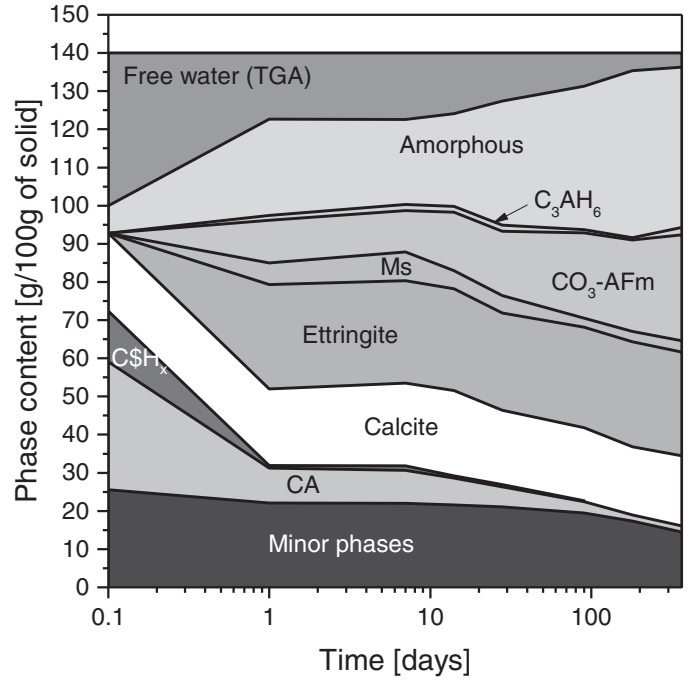

d. $60 \mathrm{CA}-40 \mathrm{HH}-20 \mathrm{Cc}$

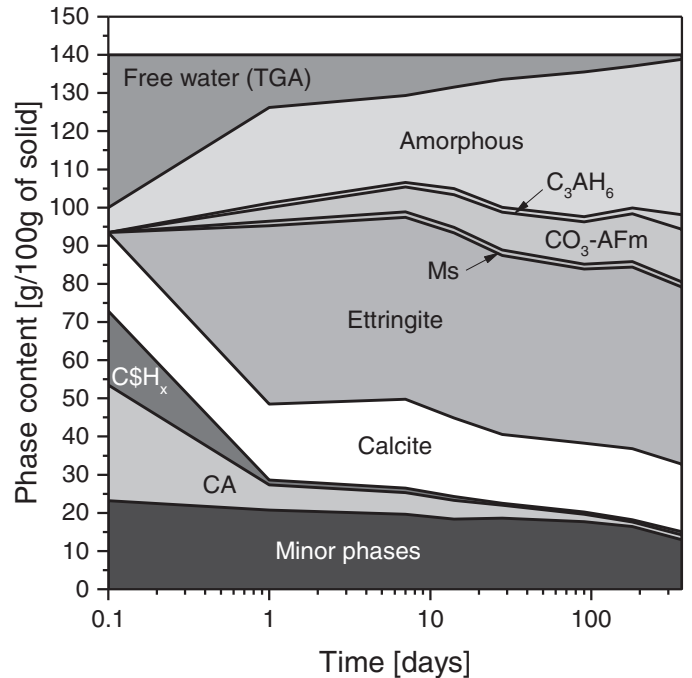

f. $55 \mathrm{CA}-45 \mathrm{HH}-20 \mathrm{Cc}$

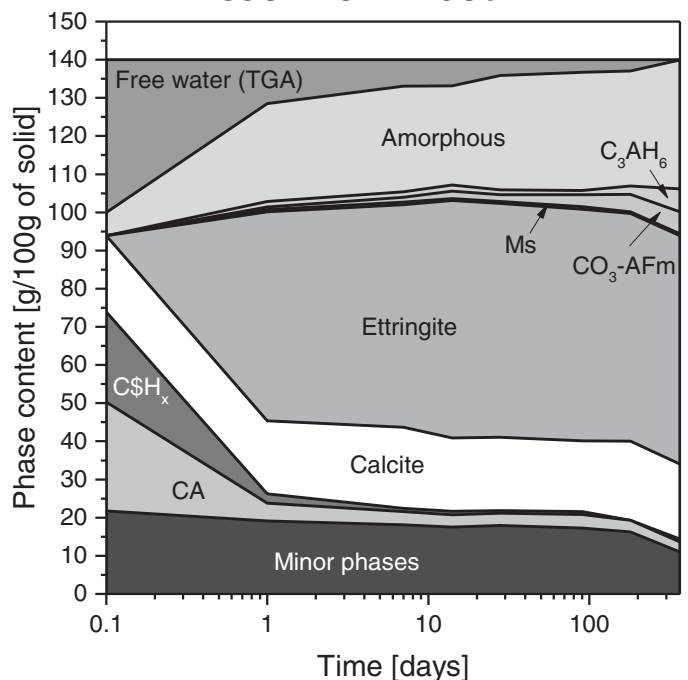

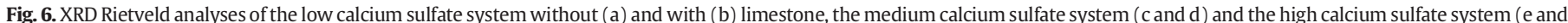

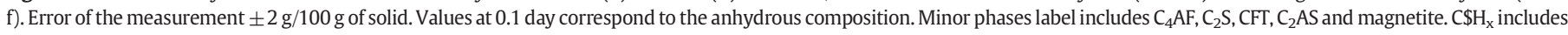

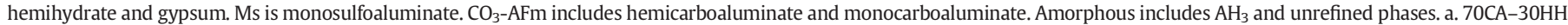
b. $70 \mathrm{CA}-30 \mathrm{HH}-20$ Cc. c. $60 \mathrm{CA}-40 \mathrm{HH}$. d. $60 \mathrm{CA}-40 \mathrm{HH}-20 \mathrm{Cc}$. e. $55 \mathrm{CA}-45 \mathrm{HH}$. f. $55 \mathrm{CA}-45 \mathrm{HH}-20 \mathrm{Cc}$. 
excess aluminate from $\mathrm{CA}$, instead of reacting with ettringite to form monosulfoaluminate. This is similar to the effect of limestone on the reaction of Portland cement [5]. There is also a small amount of $\mathrm{CO}_{3}-\mathrm{AFm}$ phases formed in the system without limestone addition due to the calcite impurity in the calcium sulfate hemihydrate.

Moving from the low sulfate system to the intermediate (60CA$40 \mathrm{HH}-20 \mathrm{Cc}$ ) and then to the high sulfate (55CA-45HH-20Cc), the amount of carboaluminate formed in the systems with limestone decreases, indicating less and less reaction of the limestone component. Calcium sulfate is in excess in the high sulfate systems, this could result in high expansion as described in [36].

The experimental phase assemblage can be compared with the thermodynamic prediction of the stable phases that can be formed. Fig. 7 shows the systems with variable proportions of hemihydrate relative to CA with $20 \mathrm{wt}$.\% limestone and a w/b ratio of 0.4 . The degree of hydration of CA and hemihydrate is set to $100 \%$ and limestone is free to react. The 3 dashed vertical lines indicate the 3 studied compositions. The amount of reacted limestone decreases with the calcium sulfate content. Above $50 \mathrm{~mol} \%$ of calcium sulfate, when there is excess of calcium sulfate, the limestone does not react anymore. The sulfate reacts with all the aluminate forming ettringite and aluminium hydroxide. Therefore no carbonate phases can form. This is the reason why in the compressive strength tests there is no or a small limestone contribution in high sulfate systems. The maximum amount of ettringite is attained at $50 \mathrm{~mol} \%$ according to the stoichiometry of reaction (1). By reducing the degree of hydration of CA, the maximum solid volume attained at $50 \mathrm{~mol} \%$ decreases and shifts to lower calcium sulfate amounts. The pH (Fig. 7, right axis) drops when there is excess of gypsum, i.e. when limestone cannot react. The same simulation was done using the full composition of CAC cement with the degree of hydration according to the experimental measurements at 1 year of hydration. The phase assemblage did not differ much from the simpler $\mathrm{CA}-\mathrm{HH}-\mathrm{Cc}$ systems; the main difference being the formation of $\mathrm{C}_{2} \mathrm{ASH}_{8}$ from $\mathrm{C}_{2} \mathrm{AS}$ present in the CAC. As this phase was not detected with XRD analyses of limestone systems, the simulation of the simpler system is presented here.

Fig. 8 shows the maximum amount of reacted limestone as a function of calcium sulfate. The values on both the $y$-axes are valid for a system where CA is $50 \mathrm{wt} . \%$ of CAC and the degree of hydration of CA is $100 \%$. The relative amount of reacted limestone is indicated on the left $y$-axis, while the relative mass of reacting limestone with respect to $\mathrm{CAC}+\mathrm{HH}$ content indicated on the right $\mathrm{y}$-axis. It can be

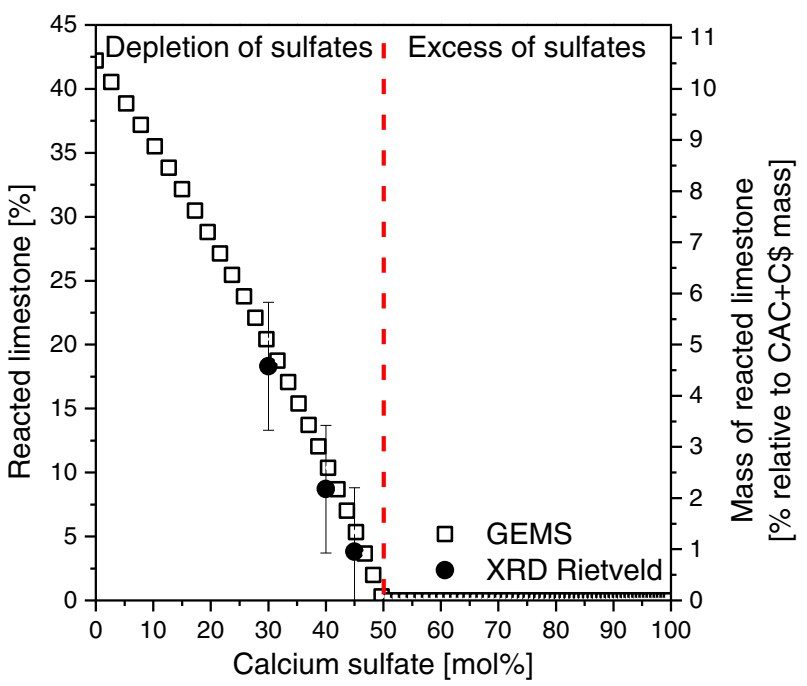

Fig. 8. Maximum amount of reacted limestone as a function of calcium sulfate content relative to $\mathrm{CA}$. On the right axis is presented the relative mass of reacting limestone with respect to CAC + HH content (for systems where CA is $50 \mathrm{wt} . \%$ of CAC). The closed circles show experimental values calculated from the amount of hemicarboaluminate and monocarboaluminate measured with XRD Rietveld analyses at 1 year.

observed how fast the amount of reacted limestone decreases when the amount of calcium sulfate increases. Above $50 \mathrm{~mol} \%$ of calcium sulfate, i.e. when there is an excess of sulfate with respect to aluminate, the ettringite is more stable than carbonate AFm therefore limestone is not consumed. Experimental values are also presented for the 3 studied compositions; the amount of reacted limestone is calculated from the amount of formed hemicarboaluminate and monocarboaluminate measured with XRD Rietveld analyses. The measured values are in agreement with the simulation. It is shown that only a small amount of limestone can react in these systems, less than $20 \mathrm{wt}$.\% of it for a substitution level of $20 \mathrm{wt} . \%$. Limestone or calcium carbonate is consumed only when the $\mathrm{SO}_{4}^{2-}$ ions are depleted in the pore solution, i.e. below $50 \mathrm{~mol} \%$ of calcium sulfate. In this case the remaining $\mathrm{Ca}^{2+}$ and $\mathrm{Al}(\mathrm{OH})^{-}{ }_{4}$ ions will react with carbonates to form hemicarboaluminate and/or monocarboaluminate.

Comparison between the masses of phases measured experimentally and that obtained with thermodynamic simulation at 1 year of

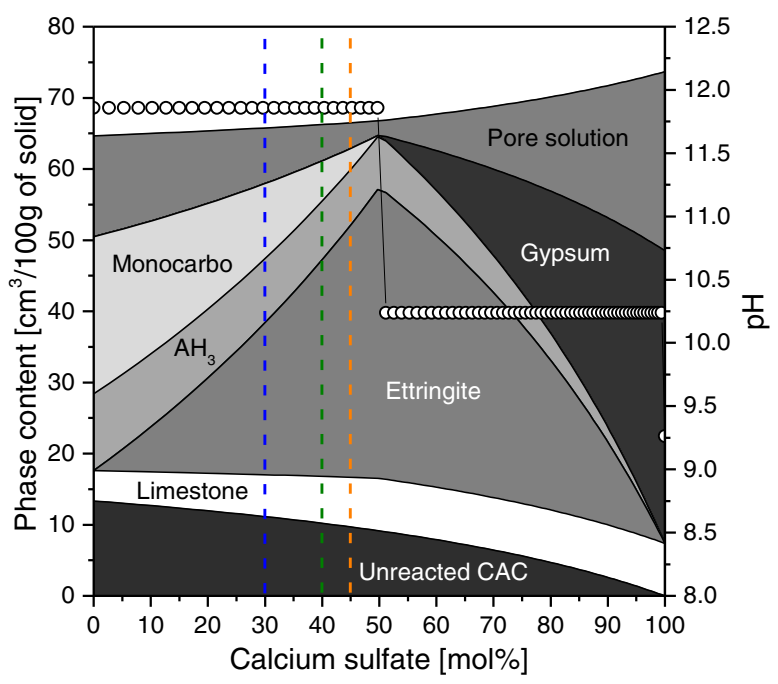

Fig. 7. Thermodynamic simulation of stable phase volumes at $20^{\circ} \mathrm{C}$ for $\mathrm{CA}-\mathrm{HH}-\mathrm{Cc}$ system with variable calcium sulfate.

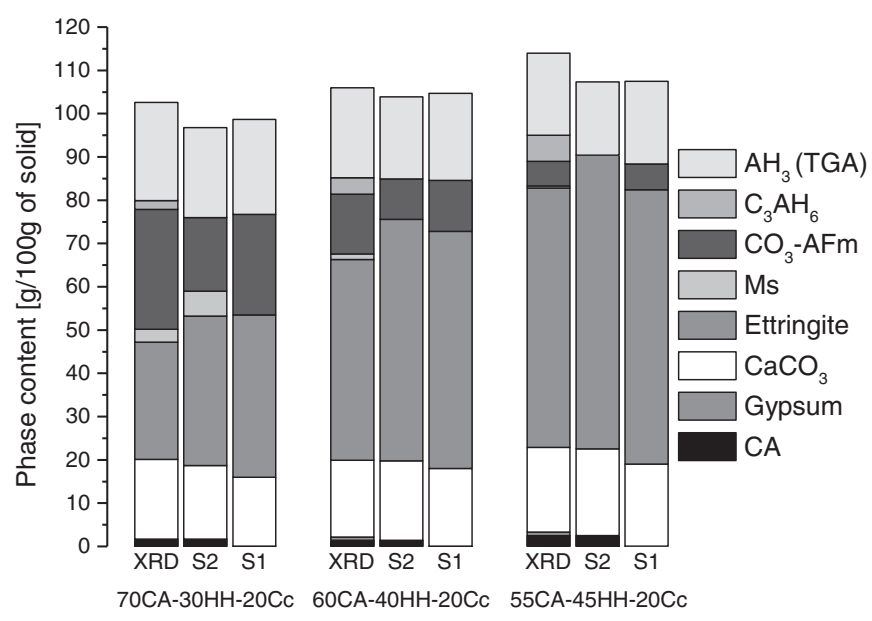

Fig. 9. Comparison between the phase quantification with XRD at 1 year and GEMS. S1 are the values from the simulation presented in Fig. 7 and S2 from the simulation with corrected CA degree of hydration. $\mathrm{CO}_{3}-\mathrm{AFm}$ from XRD includes $\mathrm{Mc}$ and $\mathrm{Hc}$. 


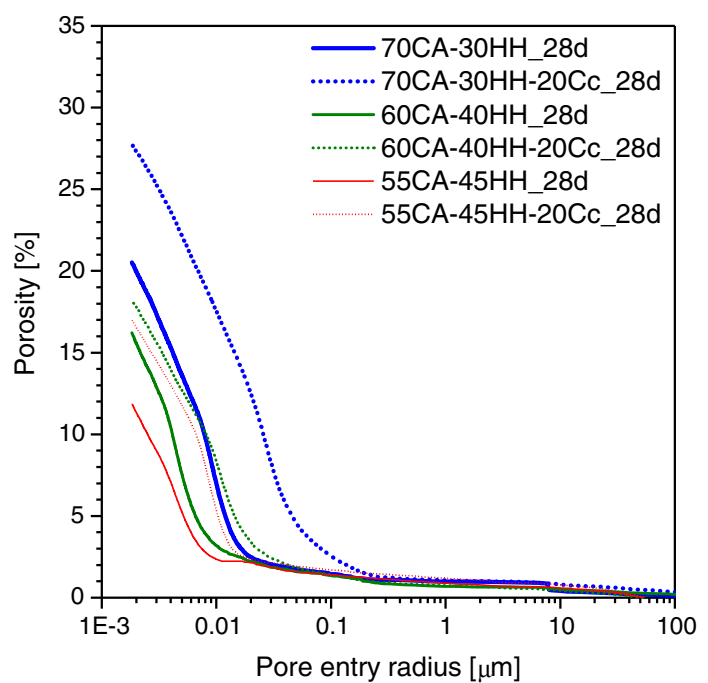

Fig. 10. MIP results of 28 days cured samples.

hydration are presented in Fig. 9. The results indicated with S2 are from the simulation with the correct degree of hydration for CA according to XRD analyses at 1 year while S1 are from the first simulation with $100 \%$ degree of hydration for CA and hemihydrate (Fig. 7). The S2 simulation is more representative of the real samples. The simulation shows only the stable phases. Therefore, hemicarboaluminate is not formed and only monocarboaluminate forms. Experimental observations show that metastable hemicarboaluminate forms initially instead of monocarboaluminate. This is probably due to faster formation kinetics of hemicarboaluminate compared to monocarboaluminate [6], kinetics that are not taken into account in the simulation. The portion marked $\mathrm{CO}_{3}-\mathrm{AFm}$ includes both monocarboaluminate and hemicarboaluminate from the XRD results. The amount of ettringite predicted thermodynamically is always above the experimental values which may be attributed to the sample preparation technique as discussed in the Materials and methods section. Hydrogarnet does not appear as a stable phase in the thermodynamic simulation even though small amounts are detected experimentally. The real composition of the hydrogarnet was not studied as it is a minor phase formed in these systems and this study

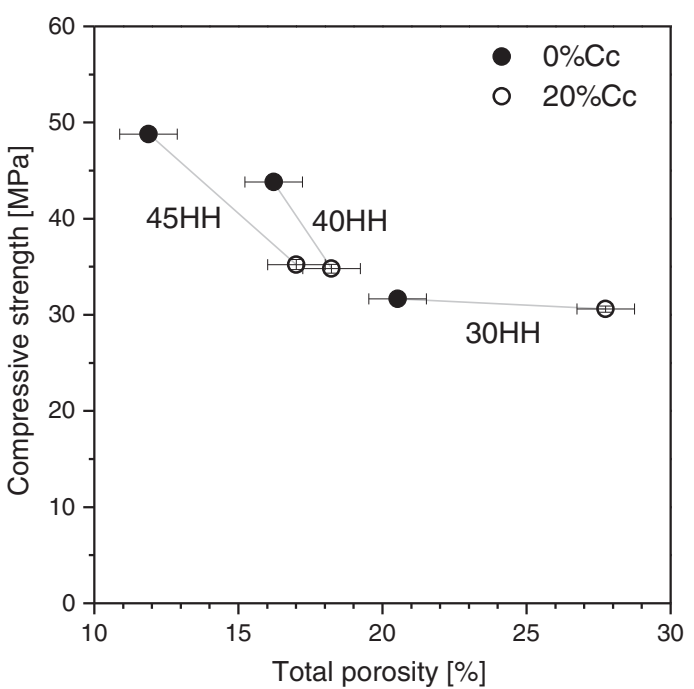

Fig. 12. Compressive strength as a function of the total porosity at 28 days measured with MIP. The 2 points corresponding to each hemihydrate amount $(30,40$ and $45 \mathrm{HH})$ are connected by lines.

focuses more on the reaction of limestone. The amount of amorphous aluminium hydroxide is estimated from TGA results as it is microcrystalline and mainly XRD amorphous. Despite these differences, the agreement between the experimental and simulated phase assemblages is quite reasonable.

\subsection{Porosity evaluation and links to compressive strength}

The porosity measured with MIP on cement paste after 28 days of hydration is presented in Fig. 10. The porosity and the threshold pore radius increase with the substitution and decrease with the calcium sulfate level.

The porosity can be calculated from the thermodynamic simulation presented in Fig. 7 by assuming that the volume of pores corresponds to the difference between the initial total volume (anhydrous solid + water) and the final solid volume (anhydrous solid + hydrates). Fig. 11a and b show the calculated porosity as a function of calcium

\section{b. Systems with $20 \%$ limestone}

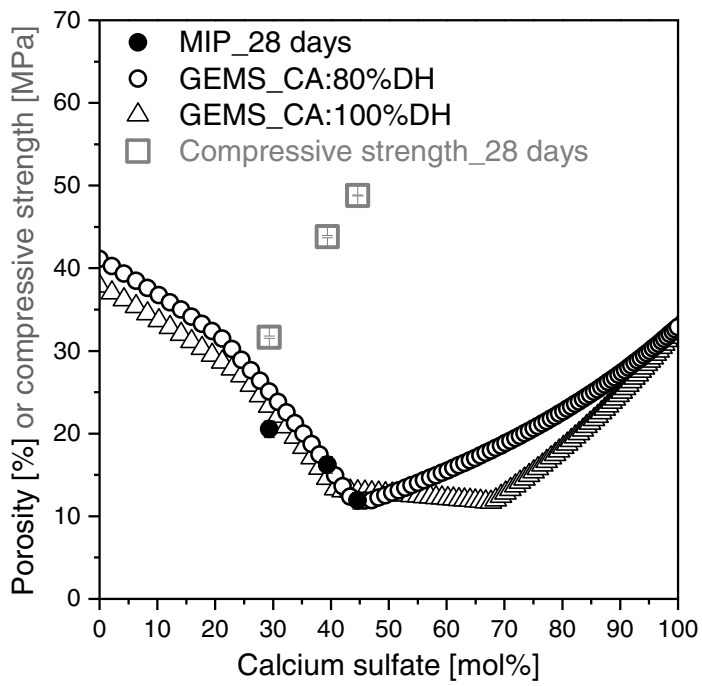

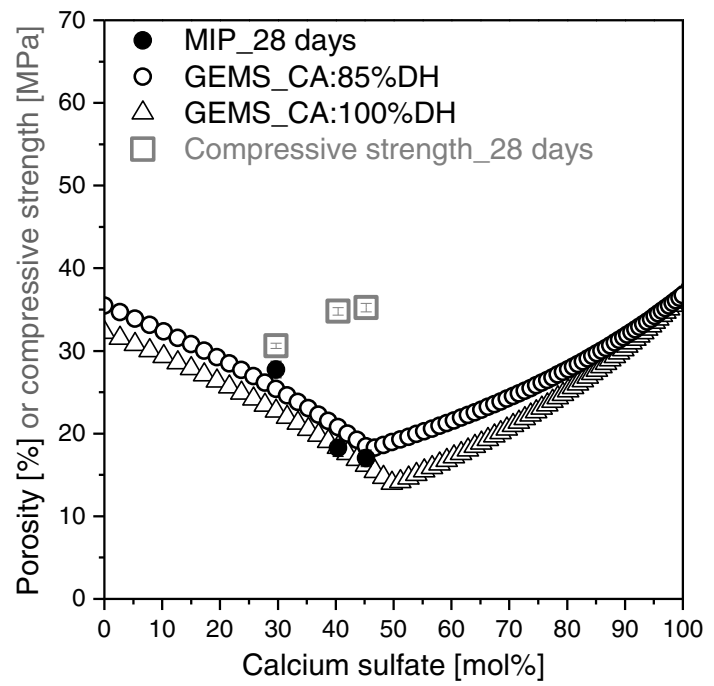

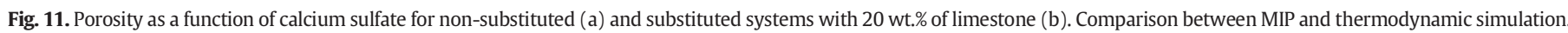
The compressive strength is also presented. a. Systems without substitution. b. Systems with $20 \%$ limestone. 
a. $70 \mathrm{CA}-30 \mathrm{HH}-20 \mathrm{Cc}$

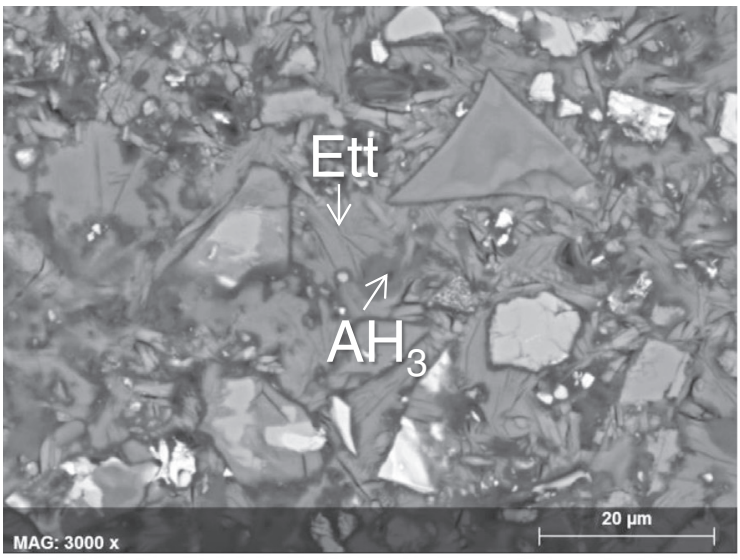

b. $60 \mathrm{CA}-40 \mathrm{HH}-20 \mathrm{Cc}$

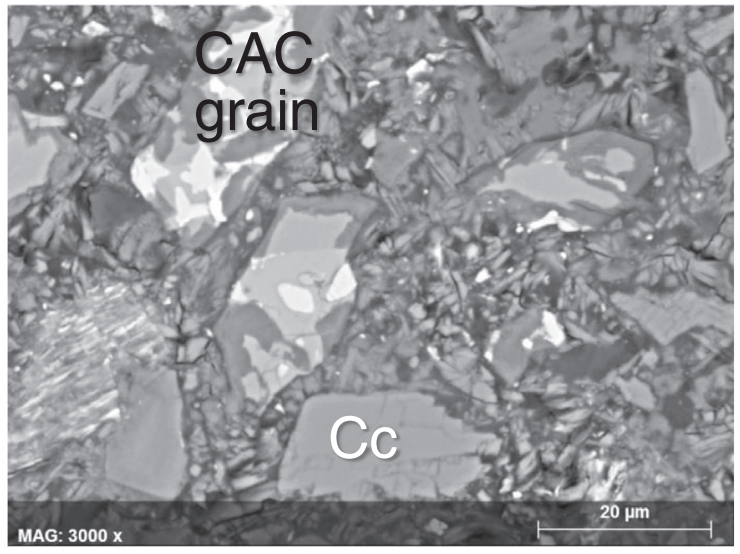

C. $55 \mathrm{CA}-45 \mathrm{HH}-20 \mathrm{Cc}$

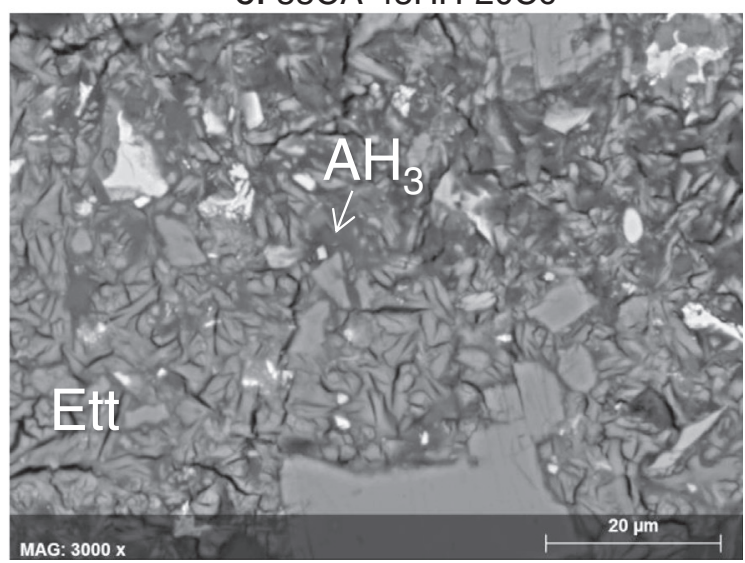

Fig. 13. SEM-BSE images of limestone samples at 28 days. a. 70CA-30HH-20Cc. b. 60CA40HH-20Cc. c. 55CA-45HH-20Cc.

sulfate content for the simulated systems without and with limestone substitution, respectively. The degree of hydration of CA varies from $80 \%$ to $100 \%$ for non-substituted systems and $85 \%$ to $100 \%$ for substituted systems. The values of $80 \%$ and $85 \%$ correspond roughly to the degree of hydration of CA at 28 days of hydration, which is the age at which the MIP measurements were made. In the systems without substitution, the water is totally consumed between 40 and $70 \mathrm{~mol} \%$ of calcium sulfate calculated for $100 \%$ degree of hydration of CA (Fig. 11a). There is very good agreement between the experimental and calculated values despite the differences in the phases assemblages discussed above and the likelihood that the sample preparation technique (solvent exchange and vacuum) may dehydrate some phases (such as ettringite) and so increase the porosity.

The mechanical properties of a material are strongly related to its porosity. The compressive strength decreases when the porosity increases $[41,42]$. This is observed in Fig. 11. The compressive strength of the mortars hydrated for 28 days increases as the porosity decreases with the calcium sulfate content.

Fig. 12 shows the compressive strength as a function of the total porosity for the systems without and with limestone substitution at 28 days of hydration. The 70CA-30HH systems have comparable compressive strength even though the porosity increases with the limestone substitution. The two other systems with higher calcium sulfate content show a reduction of the compressive strength and an increase of the total porosity when limestone is added to the system. The difference in compressive strength decreases as the amount of reacted limestone increases. This highlights the fact that two chemically different systems (with or without limestone) can have similar compressive strength even if the total porosities are different. Consequently, there is not a unique relation between porosity and compressive strength when the chemical composition changes.

\subsection{Microstructure}

The microstructures of the different systems with $20 \mathrm{wt} . \%$ limestone substitution are shown in Fig. 13. There are partially hydrated CAC grains, limestone grains and hydrates. Ettringite is characterized by a lot of small cracks. This is due to the exposure to vacuum during sample preparation and in the microscope chamber which removes water from this phase and causes shrinkage and cracking. There is a higher amount of ettringite in the high calcium sulfate system (Fig. 13c). The dark grey hydrates correspond to amorphous aluminium hydroxide and the light grey hydrates are highly intermixed phases. Plots of the element ratios ( $\mathrm{S} / \mathrm{Al}$ vs $\mathrm{Ca} / \mathrm{Al}$ ) for EDS analyses done on 200 points in the hydrated matrix at 28 days are shown in Fig. 14. The high level of intermixing of the phases is clearly visible in these plots as there is a cloud of points between the composition of $\mathrm{AH}_{3}$, ettringite, monosulfoaluminate, hemicarboaluminate and monocarboaluminate. As the calcium sulfate content increases (from Fig. 14a to b), the cloud of points moves towards the binary composition of $\mathrm{AH}_{3}$ and ettringite highly intermixed.

\section{Conclusions}

Experiments and thermodynamic simulation show that the reaction of limestone is very dependent of the balance between aluminate and sulfate. Two scenarios for the role of limestone in the CAC-calcium sulfate system are observed:

- Full reaction of calcium sulfate ( $<40 \mathrm{~mol} \%$ calcium sulfate): calcium aluminate reacts with carbonate ions from the limestone to form hemicarboaluminate and monocarboaluminate. The ettringite formed is conserved instead of reacting with CA to form calcium aluminate monosulfoaluminate.

- Excess of calcium sulfate (>40 mol\% calcium sulfate): all the calcium aluminate reacts with sulfate ions to form ettringite and aluminium hydroxide. In this case, limestone acts as filler.

Even in the system with the lowest content of calcium sulfate ( $30 \mathrm{~mol} \% \mathrm{HH}$ ) the amount of limestone which reacts is only $4 \mathrm{~g}$ for $100 \mathrm{~g}$ of anhydrous solid (one fifth of the $20 \mathrm{wt} . \%$ added). Nevertheless, this small amount of reacting limestone makes a considerable difference on the overall mineralogy. These systems have comparable or higher strengths than the systems without limestone from 7 days, despite their higher porosity. 


\section{a. $70 \mathrm{CA}-30 \mathrm{HH}-20 \mathrm{Cc}$}

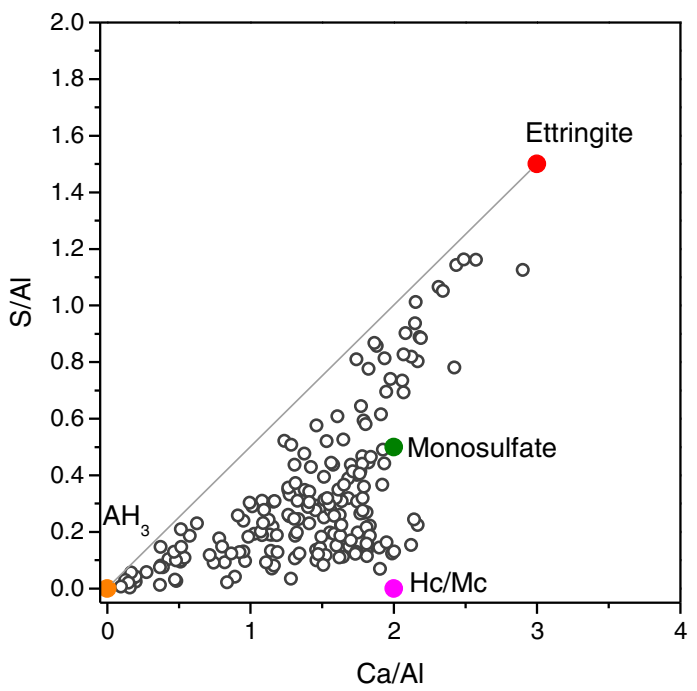

b. $55 \mathrm{CA}-45 \mathrm{HH}-20 \mathrm{Cc}$

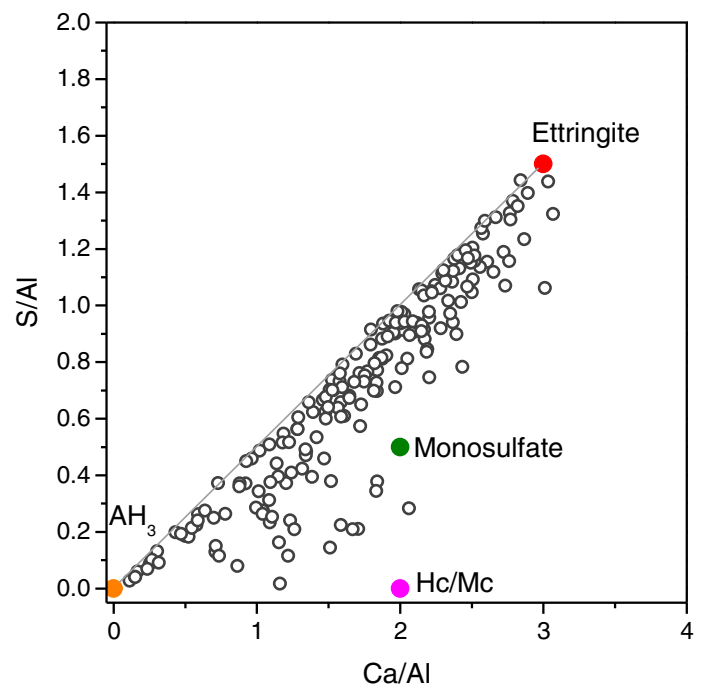

Fig. 14. SEM-EDS analyses of limestone samples at 28 days for low (a) and high (b) sulfate levels. a. 70CA-30HH-20Cc. b. 55CA-45HH-20Cc.

The systems with higher sulfate content form more ettringite and have generally higher compressive strengths. The main drawback at these high levels of calcium sulfate is that the samples can expand uncontrollably, which may lead to the destruction of the material [36].

\section{Acknowledgements}

The authors would like to thank Kerneos France for the financial support.

\section{References}

[1] L. Pelletier-Chaignat, F. Winnefeld, B. Lothenbach, C.J. Muller, Beneficial use of limestone filler with calcium sulphoaluminate cement, Constr. Build. Mater. 26 (2012) 619-627.

[2] C.W. Hargis, A. Telesca, P.J.M. Monteiro, Calcium sulfoaluminate (Ye'elimite) hydration in the presence of gypsum, calcite, and vaterite, Cem. Concr. Res. 65 (2014) 15-20.

[3] L.H.J. Martin, F. Winnefeld, C.J. Muller, B. Lothenbach, Influence of limestone on the hydration of calcium sulfoaluminate cements, Proceedings of the First International Conference on Sulphoaluminate Cement: Materials and Engineering Technology, Wuhan, China 2013, pp. 229-245.

[4] Y. Ohba, A. Nakamura, J.K. Lee, E. Sakai, M. Daimon, Influence of $\mathrm{CaCO}_{3}$ on the hydration of various types of calcium aluminates with anhydrite, Proceedings of 10th International Congress on the Chemistry of Cement, Gothenburg, Sweden 1997, p. 8.

[5] T. Matschei, B. Lothenbach, F.P. Glasser, The role of calcium carbonate in cement hydration, Cem. Concr. Res. 37 (2007) 551-558.

[6] M. Zajac, A. Rossberg, G. Le Saout, B. Lothenbach, Influence of limestone and anhydrite on the hydration of Portland cements, Cem. Concr. Res. 46 (2014) 99-108.

[7] K.D. Ingram, K.E. Daugherty, A review of limestone additions to Portland cement and concrete, Cem. Concr. Compos. 13 (1991) 165-170.

[8] P. Lawrence, M. Cyr, E. Ringot, Mineral admixtures in mortars: effect of inert materials on short-term hydration, Cem. Concr. Res. 33 (2003) 1939-1947.

[9] D.C. Creagh, J.H. Hubbell, X-ray Absorption (or Attenuation) Coefficients, International Tables for Crystallography Volume C: Mathematical, Physical and Chemical Tables, 2006.

[10] Q. Zhou, F.P. Glasser, Thermal stability and decomposition mechanisms of ettringite at $<120$ degrees C, Cem. Concr. Res. 31 (2001) 1333-1339.

[11] L. Zhang, G.W. Scherer, Comparison of methods for arresting hydration of cement, Cem. Concr. Res. 41 (2011) 1024-1036.

[12] A. Ipavec, R. Gabrovsek, T. Vuk, V. Kaucic, J. Macek, A. Meden, Carboaluminate phases formation during the hydration of calcite-containing Portland cement, J. Am. Ceram. Soc. 94 (2011) 1238-1242.

[13] S.H. Ma, R. Snellings, X.R. Li, X.D. Shen, K.L. Scrivener, Alite-ye'elimite cement: synthesis and mineralogical analysis, Cem. Concr. Res. 45 (2013) 15-20.

[14] D. Jansen, F. Goetz-Neunhoeffer, C. Stabler, J. Neubauer, A remastered external standard method applied to the quantification of early OPC hydration, Cem. Concr. Res. 41 (2011) 602-608.

[15] W. Hörkner, H. Müller-Buschbaum, Zur kristallstruktur von $\mathrm{CaAl}_{2} \mathrm{O}_{4}$, J. Inorg. Nucl. Chem. 38 (1976) 983-984.

[16] P. Ballirano, A. Maras, S. Meloni, R. Caminiti, The monoclinic I2 structure of bassanite, calcium sulphate hemihydrate $\left(\mathrm{CaSO}_{4} \cdot 0.5 \mathrm{H}_{2} \mathrm{O}\right)$, Eur. J. Mineral. 13 (2001) 985-993.
[17] A.A. Colville, S. Geller, Crystal structures of CaFeAlO and $\mathrm{CaFeAlO}_{2} 1.430 .57521 .28$ 0.72 5, Acta Crystallogr. B 28 (1972) 3196-3200.

[18] F. Goetz-Neunhoeffer, J. Neubauer, Refined ettringite $\left(\mathrm{Ca}_{6} \mathrm{Al}_{2}\left(\mathrm{SO}_{4}\right) 3(\mathrm{OH})_{12} \cdot 26 \mathrm{H}_{2} \mathrm{O}\right)$ structure for quantitative X-ray diffraction analysis, Powder Diffract. 21 (2006) 4-11.

[19] W. Mumme, R. Hill, G. Bushnell-Wye, E. Segnit, Rietveld crystal structure refinements, crystal chemistry and calculated powder diffraction data for the polymorphs of dicalcium silicate and related phases, Neues Jahrb. Mineral. Abh. 169 (1995) 35-68.

[20] R. Allmann, Refinement of the hybrid layer structure $\left[\mathrm{Ca}_{2} \mathrm{Al}(\mathrm{OH})_{6}\right]^{+} *\left[1 / 2 \mathrm{SO}_{4}\right.$ * $\left.3 \mathrm{H}_{2} \mathrm{O}\right]$, Neues Jahrbuch fur Mineralogie, Monatshefte (1977) 136-144.

[21] K. Leinenweber, K. Parise, High-pressure synthesis and crystal structure of $\mathrm{Ca} \mathrm{Fe} \mathrm{Ti}_{2}$ $\mathrm{O}_{6}$, a new perovskite structure type, J. Solid State Chem. 114 (1995) 277-281.

[22] H. Saalfeld, M. Wedde, Refinement of the crystal structure of gibbsite, $\mathrm{Al}(\mathrm{OH})_{3}, \mathrm{Z}$. Krist. 139 (1974) 129-135.

[23] I.P. Swainson, M.T. Dove, W.W. Schmahl, A. Putnis, Neutron powder diffraction study of the åkermanite-gehlenite solid solution series, Phys. Chem. Miner. 19 (1992) 185-195.

[24] M. Francois, G. Renaudin, O. Evrard, A cementitious compound with composition $3 \mathrm{CaO} \cdot \mathrm{Al}_{2} \mathrm{O}_{3} \cdot \mathrm{CaCO}_{3} \cdot 11 \mathrm{H}_{2} \mathrm{O}$, Acta Crystallogr. Sect. C: Cryst. Struct. Commun. 54 (1998) 1214-1217.

[25] N. Nakagiri, M. Manghnani, L. Ming, S. Kimura, Crystal structure of magnetite under pressure, Phys. Chem. Miner. 13 (1986) 238-244.

[26] T. Runčevski, R.E. Dinnebier, O.V. Magdysyuk, H. Pöllmann, Crystal structures of calcium hemicarboaluminate and carbonated calcium hemicarboaluminate from synchrotron powder diffraction data, Acta Crystallogr. B 68 (2012) 493-500.

[27] E. Maslen, V. Streltsov, N. Streltsova, X-ray study of the electron density in calcite, $\mathrm{CaCO}_{3}$, Acta Crystallogr. Sect. B: Struct. Sci. 49 (1993) 636-641.

[28] C. Cohen-Addad, P. Ducros, A. Durif, E. Bertaut, A. Delapalme, Détermination de la position des atomes d'hydrogène dans l'hydrogrinat $\mathrm{Al}_{2} \mathrm{O}_{3}, 3 \mathrm{CaO}, 6 \mathrm{H}_{2} \mathrm{O}$ par résonance magnétique nucléaire et diffraction neutronique, J. Phys. 25 (1964) 478-483.

[29] Á.G. De la Torre, M.-G. López-Olmo, C. Álvarez-Rua, S. García-Granda, M.A. Aranda Structure and microstructure of gypsum and its relevance to Rietveld quantitative phase analyses, Powder Diffract. 19 (2004) 240-246.

[30] R. Rinaldi, M. Sacerdoti, E. Passaglia, Stratlingite: crystal structure, chemistry, and a reexamination of its polytype vertumnite, Eur. J. Mineral. 2 (1990) 841-849.

[31] Available at http://gems.web.psi.ch/ (retrieved 12.06.2014).

[32] D.A. Kulik, T. Wagner, S.V. Dmytrieva, G. Kosakowski, F.F. Hingerl, K.V. Chudnenko, U.R. Berner, GEM-Selektor geochemical modeling package: revised algorithm and GEMS3K numerical kernel for coupled simulation codes, Comput. Geosci. 17 (2013) 1-24.

[33] W. Hummel, U. Berner, E. Curti, F.J. Pearson, T. Thoenen, Nagra/PSI chemical thermodynamic data base 01/01, Radiochim. Acta 90 (2002) 805-813.

[34] Available at http://www.empa.ch/cemdata, Version cemdata14, release date 07.05.2014 during the 4th GEMS Workshop, EMPA, Switzerland, 2014.

[35] T. Matschei, B. Lothenbach, F.P. Glasser, Thermodynamic properties of Portland cement hydrates in the system $\mathrm{CaO}-\mathrm{Al}_{2} \mathrm{O}_{3}-\mathrm{SiO}_{2}-\mathrm{CaSO}_{4}-\mathrm{CaCO}_{3}-\mathrm{H}_{2} \mathrm{O}$, Cem. Concr. Res. 37 (2007) 1379-1410.

[36] J. Bizzozero, C. Gosselin, K.L. Scrivener, Expansion mechanisms in calcium aluminate and sulfoaluminate systems with calcium sulfate, Cem. Concr. Res. 56 (2014) 190-202.

[37] W.B. Lou, B.H. Guan, Z.B. Wu, Calorimetric study of ternary binder of calcium aluminate cement, Portland-limestone cement and FGD gypsum, J. Therm. Anal. Calorim. 101 (2010) 119-127.

[38] F. Winnefeld, S. Barlag, Calorimetric and thermogravimetric study on the influence of calcium sulfate on the hydration of ye'elimite, J. Therm. Anal. Calorim. 101 (2010) 949-957. 
[39] S. Dittrich, J. Neubauer, F. Goetz-Neunhoeffer, The influence of fly ash on the hydration of OPC within the first $44 \mathrm{~h}-\mathrm{a}$ quantitative in situ XRD and heat flow calorimetry study, Cem. Concr. Res. 56 (2014) 129-138.

40] V. Kocaba, Development and evaluation of methods to follow microstructural development of cementitious systems including slags, École Polytechnique Fédérale de Lausanne 2009, p. 181.
[41] R. Féret, Compacité des mortiers hydrauliques, Ann. Ponts Chaussees 4 (1892).

[42] M. Rossler, I. Odler, Investigations on the relationship between porosity, structure and strength of hydrated Portland-cement pastes. 1. Effect of porosity, Cem. Concr. Res. 15 (1985) 320-330. 